\title{
How Menstruation Is Perceived by Adolescent School Girls in Gedeo Zone of Ethiopia?
}

\author{
Zelalem Belayneh (D), ${ }^{1}$ Moges Mareg, ${ }^{2}$ and Birhanie Mekuriaw (D) ${ }^{1}$ \\ ${ }^{1}$ Department of Psychiatry, College of Health and Medical Science, Dilla University, Dilla, Ethiopia \\ ${ }^{2}$ Department of Reproductive Health, School of Public Health, College of Health and Medical Science, Dilla University, \\ Dilla, Ethiopia
}

Correspondence should be addressed to Zelalem Belayneh; zelalembe45@gmail.com

Received 30 August 2019; Accepted 29 June 2020; Published 19 August 2020

Academic Editor: Diego Raimondo

Copyright (c) 2020 Zelalem Belayneh et al. This is an open access article distributed under the Creative Commons Attribution License, which permits unrestricted use, distribution, and reproduction in any medium, provided the original work is properly cited.

\begin{abstract}
Introduction. Perception regarding menstruation is insufficiently acknowledged. Lack of adequate perception towards menstruation may make girls vulnerable to mental, emotional, and physical problems. This might also be a reason for the failure of menstrual hygiene practice which in turn can have multiple social and health consequences. Objective. To assess the perception and correlation regarding menstruation among adolescent high school girls in Gedeo zone, Southern Ethiopia. Methods. An institutional-based cross-sectional study was conducted among a randomly selected 791 adolescent high school girls at the Gedeo zone through the multistage sampling technique. Data were collected using an interviewer-administered questionnaire. The data were entered to EPi Info version 3.5 and exported to SPSS version 20.0 for analysis. Frequency tables were used to describe study variables. Odds ratio with $95 \%$ confidence interval was computed to determine the level of significance. Result. From a total of 806 adolescent girls that were invited to participate in the study, $791(98.1 \%)$ participated. The mean $( \pm$ SD) age of respondents was $16.3( \pm 4.7)$ years. Living alone in dormitories $\{\mathrm{OR}=1.75 \mathrm{CI}=(1.07,2.85)\}$, lower maternal educational status $\{\mathrm{OR}=4.03, \mathrm{CI}=(2.41,6.74)\}$, and age of menarche before 12 years $\{\mathrm{OR}=2.07, \mathrm{CI}=(1.02,4.24)\}$ were factors statistically associated with unfavorable perception regarding menstruation. Conclusion. Most high school girls had an unfavorable perception regarding menstruation. Living alone, lower maternal educational status, and age of menarche before 12 years were factors with statistically significant association with unfavorable perception regarding menstruation. This demonstrates a need to design and implement advocacy programs.
\end{abstract}

\section{Introduction}

Menstruation is typically a universal phenomenon unique to the females during a woman's reproductive age [1]. The onset of menstruation is one of the most important changes occurring among the girls during their adolescent years, which most commonly occurs between 11 and 15 years with a mean age of 13 years [2]. This is the ideal time in which girls join high schools and colleges [3].

The onset of the first menstrual period is a qualitative event of major significance changes in a woman's life, denoting the achievement of major functional states in social-, occupational-, and health-related aspects [4]. The bodily changes associated with puberty will have an impact in the girl's physical, psychological, and social development and self-image. However, most women are uncomfortable in discussing the "topic" as it has a social taboo [5]. Women shared several misconceptions and traditional beliefs regarding menstruation [6]. Young girls experience more misperception and traditional beliefs than adult women [7] as they have no adequate information from the public, families, and peers regarding menses due to social taboo of discussion regarding these issues. The less information they might receive even commonly have some myth contents [8-10].

Lack of adequate perception towards menstruation may make girls vulnerable to mental, emotional, and physical problems, especially during their menstruating days [11-13]. 
Premenstrual dysphoric syndrome (PMS) symptoms such as depressed mood, sad, lonely, anxious, nervous, mood swings, trouble with relationships, irritable, angry, impatient, difficulty concentrating, feel out of control, cannot cope, less productive in their job or home, and avoiding social activity $[14,15]$ can also be more common among girls with poor perception of their menstruation. These symptoms impair their daily activities; reduce academic performance, increase school absenteeism, and negatively impact family relation $[16,17]$.

The manner in which a girl perceives about menstruation and its associated changes may have an impact on her response to the event of menarche [18]. Women having better knowledge and perception regarding menstruation are more likely to have safe menstrual hygiene practice. Hygienerelated practices of women during menstruation are of a considerable importance in women's health and fetus [19]. The poor menstrual hygiene practice increases vulnerability to reproductive tract infections (RTI) and GUT infection [20]. The infection can be transmitted to the offspring of the pregnant mother too [5]. This calls a comprehensive effort to minimize community misperceptions about menstruation right from their adolescent ages [21, 22]. This may help in mitigating the suffering of millions of women [23].

Despite this missed opportunity and its public health significance, perception regarding menstruation has not received adequate attention in many developing countries, especially Ethiopia [24, 25]. Therefore, the current study was aimed to assess the level of perceptions and associated factors regarding menstruation among adolescent high school girls, in Southern Ethiopia.

\section{Methods}

2.1. Study Design, Period, and Setting. An institutional-based cross-sectional study was conducted at Gedeo zone high schools from May 1, 2018, to February 1, 2019. In the zone, there are about 25 high schools serving for 2,351 female students.

2.2. Sample Size Determination and Sampling Techniques. The assumptions made for sample size calculation were a 95\% confidence interval, poor perception of menstruation [25] 39.9\% ( $p=39.9 \%)$, and a 5\% margin of the error. By adding a $10 \%$ nonresponse rate and design effects of 2 , the total sample size was 806 .

First, six high schools were randomly selected from the total of 25 high schools. The calculated sample size was proportionally allocated to the six randomly selected high schools. Then, the systematic random sampling technique was used to select individual participants in each high school through intervals $(K)$. The interval $(K)$ was calculated for each high school by dividing the total amount of eligible students (age of 13 and above, regular menstruation in the last two consecutive cycles, currently not pregnant, or breast feeding) to the proportionally allocated samples to be drawn from that high school. The first participant was selected by the lottery method between 1 and $K$. Finally, the
" $K$ " value was added until the proposed samples size was addressed.

2.3. Data Collection Instruments and Procedures. An interviewer-administered questionnaire was used for the data collection. The questionnaire had different domains, including sociodemographic profile, perception-related questions, and Oslo 3-item social support scale.

Level of perception was assessed using a series of 20 Likert scale questions adopted from different literatures $[8,11,26-29]$. The questions had a range of scores ( 0 = strongly disagree, $1=$ disagree, 2 =agree, and $3=$ strongly disagree) for correct statements and scored reversely for false sentences. Individuals who score equal to or above the mean (50\%) of the total scores (60) were considered as having good perception.

The questionnaire was prepared in English and translated to Amharic and Gedeufa (the commonly spoken languages in the study area) and back to English to check its consistency. Pretest was done at the Chuko high school among 5\% (40) of female high school students.

Before the data collection, ethical clearance was obtained from the Institutional Review Board (IRB) of Dilla University. Permission letter was also obtained from the Gedeo Zone Educational Bureau. All participants above the age of 16 and the parents/guardians of participants below the age of 16 were requested to provide written consent after a brief explanation about the purpose and objectives of the study. Participants were also informed of their right to refuse or withdraw their participation at any time they want, and they would face no harm due to their refusal. The data were collected by twelve trained psychiatric nurses supervised by four MSc level mental health professionals. Full freedom was given to study participants to refuse or discontinue participation at any time they want. Personal identifiers like name or phone number have never been recorded at the time of data collection, and the collected data were kept confidential.

2.4. Data Processing and Analysis. First, the collected data were checked for their completeness and consistency. The data were then entered to Epi Info version 3.5 and exported the Statistical Package for Social Science (SPSS, version 20) for analysis. Descriptive statics were computed to measure the level of perception and distribution of the study variables. Bivariable and multivariable logistic regression was computed to identify factors associated with poor perception regarding menstruation. All variables with a $p$ value less than 0.25 in the bivariable logistic regression were entered together into a multivariable logistic regression in order to control the potential confounders. In the multivariable logistic regression analysis, variables with a $p$ value of less than 0.05 were considered as statistically significant.

\section{Result}

From a total of 806 adolescent girls invited to participate in the study, $791(98.1 \%)$ participated. The mean $( \pm S D)$ age of respondents was $16.3( \pm 4.7)$ years. Majority $(67 \%)$ were within the 
age ranges of $15-18$ years. More than half (58.3\%) were Gedeo in ethnicity, and $32.2 \%$ were living with their parents (Table 1).

3.1. Level of Menstrual Perception. There were numerous traditional beliefs and perceptions regarding menstruation among adolescent high school girls in the Gedeo zone. "Disease as a cause of menses" and "Menses as a lifelong process" were most commonly endorsed misconceptions shared by $51.8 \%$ and $50.2 \%$, respectively. Generally, about $540(68.3 \%)$ of participants had an unfavorable perception (scored $<50 \%$ of the total score of the perception related questions) (Table 2).

3.2. Factors Associated with Perception towards Menstruation. Both bivariable and multivariable logistic regression analyses were done to assess factors associated with perception towards menstruation. Living alone in dormitories, lower maternal educational status, and age of menarche before 12 years were factors with statistically significant association with unfavorable perception regarding menstruation (Table 3).

\section{Discussion}

There are many traditional beliefs and perceptions shared by adolescent girls regarding menstruation both in developing and developed nations, and the problem becomes higher among adolescent high school girls [8]. The findings of this research work confirm this conclusion. Accordingly, the finding of this study showed that $540(68.3 \%)$ of adolescents high school girls in the Gedeo zone had an unfavorable perception regarding menstruation. This is in line with a study conducted in Southern Ethiopia in which $60.1 \%$ of high school girls had poor knowledge regarding menses [25] and in Northern Ethiopia [6] and Nigeria, which states that perceptions regarding menstruation are poor, and practices are often incorrect among young girls [9].

The findings of the current study showed that Gedeo zone high school girls had more unfavorable perceptions than reports of a study conducted in India in which $61.3 \%$ of adolescent girls have good awareness about menstruation [28]. However, the findings of this study showed a better perception of high school girls towards menstruation as compared to a similar study conducted in India, which revealed that only $28.7 \%$ had knowledge regarding menstruation [8].

This study also assessed the correlation of perception towards menstruation among high school girls. Accordingly, the odds of having poor perception regarding menstruation among girls who are living alone were 1.75 times higher $\{\mathrm{OR}=1.75 \mathrm{CI}=(1.07,2.85)\}$ as compared to girls who are living with their parents. This finding is parallel to the conclusions of other studies. This might be due to the lack of access to adequate information from their mother, sisters, and other family members [19].

Maternal educational level has a statistically significant association with poor perception of menstruation
TABle 1: Sociodemographic characteristics of adolescent high school girls in Gedeo zone, Southern Ethiopia $(N=791)$.

\begin{tabular}{|c|c|c|c|}
\hline Variable & Categories & Frequency & Percentage \\
\hline \multirow{3}{*}{ Age in years } & $<15$ years & 185 & 23.4 \\
\hline & $15-18$ years & 530 & 67.0 \\
\hline & $>18$ years & 76 & 9.6 \\
\hline \multirow{3}{*}{ Living with } & Parents & 290 & 31.3 \\
\hline & Relatives & 253 & 27.3 \\
\hline & Peers & 215 & 23.2 \\
\hline \multirow{2}{*}{ Residency } & Rural & 548 & 69.3 \\
\hline & Town & 243 & 30.7 \\
\hline \multirow{4}{*}{ Religion } & Protestant & 461 & 58.3 \\
\hline & Orthodox & 206 & 26.0 \\
\hline & Muslim & 64 & 8.1 \\
\hline & Others & 60 & 7.6 \\
\hline \multirow{5}{*}{ Ethnicity } & Gedeo & 409 & 51.7 \\
\hline & Oromo & 182 & 23.0 \\
\hline & Amhara & 133 & 16.8 \\
\hline & Guragie & 25 & 3.2 \\
\hline & ${ }^{*}$ Others & 42 & 5.3 \\
\hline \multirow{3}{*}{ Birth order } & First & 285 & 36.0 \\
\hline & In between & 326 & 41.2 \\
\hline & Last & 180 & 22.8 \\
\hline \multirow{5}{*}{$\begin{array}{l}\text { Maternal } \\
\text { education }\end{array}$} & $\begin{array}{l}\text { Unable to read and } \\
\text { write }\end{array}$ & 278 & 35.1 \\
\hline & Able to read and write & 138 & 17.4 \\
\hline & Primary & 213 & 26.9 \\
\hline & Secondary & 73 & 9.2 \\
\hline & Diploma and above & 89 & 11.3 \\
\hline \multirow{5}{*}{$\begin{array}{l}\text { Paternal } \\
\text { education }\end{array}$} & $\begin{array}{l}\text { Unable to read and } \\
\text { write }\end{array}$ & 202 & 25.5 \\
\hline & Able to read and write & 212 & 26.8 \\
\hline & Primary & 271 & 34.3 \\
\hline & Secondary & 44 & 5.6 \\
\hline & Diploma and above & 62 & 7.8 \\
\hline \multirow{4}{*}{ Living with } & Parents & 253 & 32.0 \\
\hline & Relatives & 224 & 28.3 \\
\hline & Peers & 172 & 21.7 \\
\hline & Alone & 142 & 18.0 \\
\hline \multirow{2}{*}{ Family structure } & Joint & 253 & 32.0 \\
\hline & Nuclear & 538 & 68.0 \\
\hline \multirow{3}{*}{ Age of menarche } & $<121$ years & 195 & 24.7 \\
\hline & $12-15$ years & 535 & 67.6 \\
\hline & $>15$ years & 61 & 7.7 \\
\hline
\end{tabular}

* Others refer to Siltie, Wolayita, and Tigrie.

among high school girls [25]. Accordingly, the current study showed that girls whose mother is unable to read and write were 4.03 times more likely to have poor perception towards menstruation $\{\mathrm{OR}=4.03, \mathrm{CI}=(2.41$, 6.74) $\}$ as compared to girls whose mother's educational level is diploma and above. This might be explained by the fact that mothers with higher educational levels can discuss with their daughters freely about the truths of menstruation, and mothers with lower educational status might not be open to discuss regarding menstruation or might deliver misperceived ideas [29].

Similarly, girls whose menarche is before 12 years of age were 2.07 times more likely to have poor perception regarding 
Table 2: Perception regarding menstruation among adolescent high school girls in Gedeo zone, Southern Ethiopia, 2019 ( $N=791)$.

\begin{tabular}{|c|c|c|c|c|c|}
\hline \multicolumn{2}{|c|}{ Question } & $\begin{array}{c}\text { Strongly disagree }(0) \\
(\%)\end{array}$ & $\begin{array}{c}\text { Disagree (1) } \\
(\%)\end{array}$ & $\begin{array}{l}\text { Agree (2) } \\
(\%)\end{array}$ & $\begin{array}{l}\text { Strongly agree (3) } \\
(\%)\end{array}$ \\
\hline \multicolumn{6}{|c|}{ Menses } \\
\hline 1 & It is a normal phenomena & 8.0 & 5.9 & 10.4 & 75.5 \\
\hline 2 & It is unique to females & 24.7 & 17.7 & 6.8 & 50.8 \\
\hline 3 & It is a lifelong process & 27.1 & 16.6 & 6.2 & 50.2 \\
\hline 4 & $\begin{array}{l}\text { It will be stopped after initiation of sexual } \\
\text { intercourse }\end{array}$ & 31.6 & 13.5 & 15.3 & 18.6 \\
\hline 5 & It is a sign of conception & 61.8 & 11.0 & 12.4 & 14.8 \\
\hline 6 & It has foul smell & 13.5 & 13.1 & 13.8 & 59.5 \\
\hline 7 & It is pathological & 58.9 & 8.05 & 11.8 & 21.4 \\
\hline \multicolumn{6}{|c|}{ Sources } \\
\hline 8 & Uterus & 39.1 & 52 & 23.1 & 32.6 \\
\hline 9 & Bladder & 41.8 & 8.3 & 18.5 & 31.4 \\
\hline 10 & Vagina & 22.8 & 18.5 & 11.5 & 47.3 \\
\hline 11 & Abdomen & 40.3 & 13.5 & 20.5 & 25.7 \\
\hline \multicolumn{6}{|c|}{ Causes } \\
\hline 12 & Hormonal & 33.9 & 10.7 & 18.6 & 36.8 \\
\hline 13 & Diseases & 51.8 & 11.6 & 16.3 & 20.7 \\
\hline 14 & Curse & 51.1 & 10.5 & 8.7 & 27.7 \\
\hline \multicolumn{6}{|c|}{ What is good to be done during menstruation } \\
\hline 15 & $\begin{array}{l}\text { Not allowed touch others during menstruation } \\
\text { period }\end{array}$ & 51.1 & 11.9 & 22.5 & 14.5 \\
\hline 16 & Not allowed to go to kitchens during menses & 53.2 & 12.8 & 13.7 & 20.4 \\
\hline 17 & It is not good to discuss about menses & 50.1 & 10.7 & 13.3 & 25.9 \\
\hline 18 & $\begin{array}{c}\text { Activities done by menstruating woman are not } \\
\text { blessed }\end{array}$ & 39.6 & 15.7 & 22.4 & 22.4 \\
\hline 19 & Being free from menses is a fate & 37.7 & 17 & 22.3 & 22.5 \\
\hline
\end{tabular}

TABLE 3: Bivariable and multivariable analysis of factors associated with perception regarding menstruation among adolescent high school girls in Gedeo zone, Southern Ethiopia $(N=791)$.

\begin{tabular}{|c|c|c|c|c|c|}
\hline \multirow{2}{*}{ Variables } & \multirow{2}{*}{ Categories } & \multicolumn{2}{|c|}{ Level of perception } & \multirow{2}{*}{ COR 95\% CI } & \multirow{2}{*}{ AOR 95\% CI } \\
\hline & & Good & Poor & & \\
\hline \multirow{2}{*}{ Residency } & Town & 165 & 383 & 1.00 & 1.00 \\
\hline & Rural & 86 & 157 & $1.27(0.92,1.75)$ & $1.33(0.95,1.87)$ \\
\hline \multirow{3}{*}{ Birth order } & First & 86 & 199 & $0.60(0.43,0.85)$ & $1.22(0.79,1.87)$ \\
\hline & In between & 105 & 221 & $2.53(1.33,4.83)$ & $1.07(0.71,1.62)$ \\
\hline & Last & 60 & 120 & 1 & 1 \\
\hline \multirow{4}{*}{ Living with } & Parents & 83 & 170 & 1 & 1 \\
\hline & Relatives & 80 & 144 & $0.87(0.60,1.28)$ & $0.98(0.66,1.46)$ \\
\hline & Peers & 55 & 117 & $1.03(0.68,1.57)$ & $1.07(0.69,1.64)$ \\
\hline & Alone & 33 & 109 & $1.61(1.61,2.57)$ & $1.75(1.07,2.85)^{*}$ \\
\hline \multirow{5}{*}{ Maternal education } & Unable to read and write & 64 & 214 & $3.91(2.37,6.46)$ & $4.03(2.41,6.74)^{* * *}$ \\
\hline & Able to read and write & 42 & 96 & $2.6(1.54,4.64)$ & $2.60(1.48,4.57)$ \\
\hline & Primary & 67 & 146 & $2.55(1.53,4.23)$ & $2.47(1.47,4.14)$ \\
\hline & Secondary & 30 & 43 & $1.67(0.98,3.13)$ & $1.74(0.91,3.29)$ \\
\hline & Diploma and above & 48 & 41 & 1.00 & 1 \\
\hline \multirow{3}{*}{ Age at menarche } & $<12$ years & 169 & 366 & $1.62(0.76,3.41)$ & $2.07(1.02,4.24)^{* *}$ \\
\hline & $12-15$ years & 69 & 126 & $1.82(0.43,3.96)$ & $1.19(0.82,1.73)$ \\
\hline & $>15$ years & 13 & 48 & 1 & 1 \\
\hline
\end{tabular}

${ }^{*} p$ value $<0.05,{ }^{* *} p<0.01$, and ${ }^{* * *} p<0.001$.

menstruation $\{\mathrm{OR}=2.07, \mathrm{CI}=(1.02,4.24)\}$ as compared to girls whose menarche was after 15 years. This might be explained as girls whose menarche was starting late can have better opportunity to share good knowledge and prepare and adjust themselves for menstruation than girls whose menarche was stated earlier [3, 21, 29].

\section{Conclusion}

There were numerous traditional beliefs and perceptions regarding menstruation among adolescent high school girls in the Gedeo zone. Most (68.3\%) of the high school girls had unfavorable perceptions regarding menstruation. Living 
alone in dormitories, lower maternal educational status, and age of menarche before 12 years were factors with statistically significant association with unfavorable perception regarding menstruation. This demonstrates a need to design and implement awareness creation and advocacy programs. Special attention is expected to be given to girls who live alone and who have lower maternal educational status and lower age of menarche.

\section{Data Availability}

All the data included in the manuscript have been included in the form of tables. The deidentified raw data can be accessed up on request from the author $\mathrm{ZB}$ through zelalembe45@gmail.com.

\section{Conflicts of Interest}

The authors declare that they have no conflicts of interest.

\section{Authors' Contributions}

All authors participated in the conception, proposal writing, data analysis, drafting, or revising the article and gave final approval of the version to be published. All authors agreed to be accountable for all aspects of the work.

\section{Acknowledgments}

All authors would like to acknowledge Dilla University for the provision of ethical clearance. The authors would also like to thank the Gedeo Zone Educational Bureau staffs and school directors for their unreserved help in all stages of this research work.

\section{References}

[1] S. Matsumoto, Y. Mogami, and S. Ohkuri, "Statistical studies on menstruation; a criticism on the definition of normal menstruation," Gunma Journal of Medical Sciences, vol. 11, no. 4, pp. 294-318, 1962.

[2] E. MacGregor, H. Chia, R. Vohrah, and M. Wilkinson, "Migraine and menstruation: a pilot study," Cephalalgia: an International Journal of Headache, vol. 10, no. 6, pp. 305-310, 1990.

[3] E. Ayele and Y. Berhan, "Age at menarche among in-school adolescents in Sawla town, south Ethiopia," Ethiopian Journal of Health Sciences, vol. 23, no. 3, pp. 189-200, 2013.

[4] S. Lee, "Health and sickness: the meaning of menstruation and premenstrual syndrome in women's lives," Sex Roles, vol. 46, no. 1/2, pp. 25-35, 2002.

[5] A. Dasgupta and M. Sarkar, "Menstrual hygiene: how hygienic is the adolescent girl?" Indian Journal of Community Medicine, vol. 33, no. 2, p. 77, 2008.

[6] L. L. Wall, S. Belay, A. Bayray, S. Salih, and M. Gabrehiwot, "A community-based study of menstrual beliefs in Tigray, Ethiopia," International Journal of Gynecology \& Obstetrics, vol. 135, no. 3, pp. 310-313, 2016.

[7] M. Sommer, N. Ackatia-Armah, S. Connolly, and D. Smiles, "A comparison of the menstruation and education experiences of girls in Tanzania, Ghana, Cambodia and Ethiopia,"
Compare: A Journal of Comparative and International Education, vol. 45, no. 4, pp. 589-609, 2015.

[8] D. Shanbhag, R. Shilpa, N. D’Souza, P. Josephine, J. Singh, and B. Goud, "Perceptions regarding menstruation and practices during menstrual cycles among high school going adolescent girls in resource limited settings around Bangalore city, Karnataka, India," International Journal of Collaborative Research on Internal Medicine \& Public Health, vol. 4, no. 7, p. 1353, 2012.

[9] E. D. Adinma and J. I. Adinma, "Perceptions and practices on menstruation amongst Nigerian secondary school girls," African Journal of Reproductive Health, vol. 12, no. 1, pp. 74-83, 2008.

[10] R. Bhatt and M. Bhatt, "Perceptions of Indian women regarding menstruation," International Journal of Gynecology \& Obstetrics, vol. 88, no. 2, pp. 164-167, 2005.

[11] A. Kumar and K. Srivastava, "Cultural and social practices regarding menstruation among adolescent girls," Social Work in Public Health, vol. 26, no. 6, pp. 594-604, 2011.

[12] M. K. Goel and M. Kundan, "Psycho-social behaviour of urban Indian adolescent girls during menstruation," Australasian Medical Journal, vol. 4, no. 1, pp. 49-52, 2011.

[13] T. Takeda, S. Koga, and N. Yaegashi, "Prevalence of premenstrual syndrome and premenstrual dysphoric disorder in Japanese high school students," Archives of Women's Mental Health, vol. 13, no. 6, pp. 535-537, 2010.

[14] T. O. Nwankwo, U. U. Aniebue, and P. N. Aniebue, "Menstrual disorders in adolescent school girls in enugu, Nigeria," Journal of Pediatric and Adolescent Gynecology, vol. 23, no. 6, pp. 358-363, 2010.

[15] U. Halbreich, J. Borenstein, T. Pearlstein, and L. S. Kahn, “The prevalence, impairment, impact, and burden of premenstrual dysphoric disorder (PMS/PMDD)," Psychoneuroendocrinology, vol. 28, no. Suppl 3, pp. 1-23, 2003.

[16] A. O. Adewuya, O. M. Loto, and T. A. Adewumi, "Premenstrual dysphoric disorder amongst Nigerian university students: prevalence, comorbid conditions, and correlates," Archives of Women's Mental Health, vol. 11, no. 1, pp. 13-18, 2008.

[17] F. E. Omu, R. Al-Marzouk, H. Delles, N. O. Oranye, and A. E. Omu, "Premenstrual dysphoric disorder: prevalence and effects on nursing students' academic performance and clinical training in Kuwait," Journal of Clinical Nursing, vol. 20, no. 19-20, pp. 2915-2923, 2011.

[18] U. Lawan, W. Y. Nafisa, and A. B. Musa, "Menstruation and menstrual hygiene amongst adolescent school girls in Kano, Northwestern Nigeria," African Journal of Reproductive Health, vol. 14, no. 3, pp. 201-207, 2010.

[19] B. S. Czerwinski, "Adult feminine hygiene practices," Applied Nursing Research, vol. 9, no. 3, pp. 123-129, 1996.

[20] T. K. Tegegne and M. M. Sisay, "Menstrual hygiene management and school absenteeism among female adolescent students in northeast Ethiopia," BMC Public Health, vol. 14, no. 1, p. 1118, 2014.

[21] M. Fakhri, Z. Hamzehgardeshi, N. A. H. Golchin, and A. Komili, "Promoting menstrual health among Persian adolescent girls from low socioeconomic backgrounds: a quasiexperimental study," BMC Public Health, vol. 12, no. 1, p. 193, 2012.

[22] M. Poureslami and F. Osati-Ashtiani, "Assessing knowledge, attitudes, and behavior of adolescent girls in suburban districts of Tehran about dysmenorrhea and menstrual hygiene," Journal of International Women's Studies, vol. 3, no. 2, pp. 51-61, 2002. 
[23] M. Nair, D. Chacko, M. R. Darwin, K. Padma, B. George, and P. Russell, "Menstrual disorders and menstrual hygiene practices in higher secondary school girls," The Indian Journal of Pediatrics, vol. 79, no. 1, pp. 74-78, 2012.

[24] V. Chandra-Mouli and S. V. Patel, "Mapping the knowledge and understanding of menarche, menstrual hygiene and menstrual health among adolescent girls in low-and middleincome countries," Reproductive Health, vol. 14, no. 1, p. 30, 2017.

[25] S. P. Upashe, T. Tekelab, and J. Mekonnen, “Assessment of knowledge and practice of menstrual hygiene among high school girls in western Ethiopia," BMC Women's Health, vol. 15 , no. 1 , p. 84,2015

[26] P. Adhikari, B. Kadel, S. Dhungel, and A. Mandal, "Knowledge and practice regarding menstrual hygiene in rural adolescent girls of Nepal," Kathmandu University Medical Journal (KUMJ), vol. 5, no. 3, pp. 382-386, 2007.

[27] V. Chothe, J. Khubchandani, D. Seabert et al., "Students' perceptions and doubts about menstruation in developing countries," Health Promotion Practice, vol. 15, no. 3, pp. 319-326, 2014.

[28] K. Kamaljit, B. Arora, K. Singh, and N. Neki, "Social beliefs and practices associated with menstrual hygiene among adolescent girls of Amritsar, Punjab, India," JIMSA, vol. 25, no. 2, pp. 69-70, 2012.

[29] M. Sommer and M. Sahin, "Overcoming the taboo: advancing the global agenda for menstrual hygiene management for schoolgirls," American Journal of Public Health, vol. 103, no. 9, pp. 1556-1559, 2013. 